\title{
QUINCE POEMAS DE CATULO
}

Ramón Irigoyen

Escribió un moralista francés que el único exceso absolutamente aconsejable al hombre es el exceso de la gratitud. Por eso comienzo esta nota agradeciéndole a Ernesto Cardenal su tan reciente como deplorable edición de unos poemas de Catulo (y también de Marcial) que ha masacrado con la alegría propia del trapense que aprendió el latín leyendo el breviario en castellano. Desconozco el clima de los conventos de Nicaragua, pero, a juzgar por estas espantosas traducciones de Sor Ernesto, en los cabarés trapenses todo el año debe hacer bochorno. Me callo el nombre de la editorial para que nadie caiga en la tentación de hojearlo. Muchas gracias, Padre, pero le hubiésemos agradecido más que nos hubiese ahorrado este bodrio. Su mal ejemplo ha surtido efecto. Usted, junto con Jaime Siles, es el responsable de que yo me haya animado a sacar estas traducciones. Como digo, Jaime Siles es el segundo culpable. Su espléndida traducción del poema 80 de Catulo publicada en la Revista Hiperión casi me hizo saltar de alegría porque para mí es la primera traducción al castellano de un poema de Catulo hecha con todo el rigor filológico y la gracia poética que el oficio de traductor requiere. Escribo gracia deliberadamente recordando aquel texto de Pessoa en que dice que para ser poeta $-\mathrm{y}$ no sería exagerado decir que también para ser traductorse requiere inteligencia, sensibilidad, imaginación y, lo más difícil, gracia.

De los varios traductores de Catulo al castellano vaya mi homenaje para Juan Petit que en la España de 1950 publicó una edición completa en prosa, si bien pedestre, bastante digna y que en alguna ocasión incluso se atreve con las obscenidades del original. Agotada la edición de Juan Flors, ha sido reeditada por Los Libros de la frontera. 


\section{RAMON IRIGOYEN}

Miguel Dolç editó un Catulo completo en Alma mater en prosa también digna, rupestre y puritana.

Aprovecho la ocasión de esta nota para felicitar a Amparo Gaos y al poeta mexicano Rubén Bonifaz Nuño que en sus traducciones de Catulo recogidas en su Antología de la poesía latina publicada por la $U N A M$ han dado -entre otras - una buena prueba de sensibilidad lingüística al traducir el plural deliciae que en latín carece de singular por delicia, cuando es la aposición de un sustantivo en singular, (puede verse en los poemas II, III, VI y algunos más que no tengo la paciencia de citar), cuando todos los traductores españoles que conozco - desde don Juan Quirós de los Ríos a Juan Petit pasando por Pérez del Camino, Herrero Llorente y Miguel Dolç- atentando contra la concordancia numeral lo traducen equivocadamente por delicias. ( $\mathrm{Y}$ así el passer, deliciae meae puellae, según su particular interpretación del passer, lo traducen por gorrión, delicias de mi amada, o por pajarillo, delicias de mi amada, y no por pájaro, delicia de mi amada).

Escribía el Abate Marchena en 1820 de los epigramas de Catulo que "gracias a la mentida delicadeza de nuestras acendradas costumbres y nuestros cosquillosos idiomas, escandalizarían a la mayor parte de nuestros lectores, si a traducirlos palabra por palabra nos atreviésemos". Escribía esto al iniciarse el trienio liberal que naturalmente terminó como solemos terminar aquí estos trienios. Como hace ya tres años largos que murió el Caudillo -o, lo que es lo mismo, la ola de pornografía que nos invade ya ha cumplido un trienio- por si acaso me apresuro a mandar a la imprenta estos textos profanos de Catulo.

El texto latino que he seguido es el de la Oxford University Press en su edición de 1958, preparada por R. A. B. Mynors. Pero en el poema 41 (vv. 7-8) sigo la lectura de Schawe.

Elijo estos quince poemas un poco al azar entre los sesenta que de Catulo tengo traducidos. Si se siguen editando traducciones tan malas como las del trapense de Nicaragua y tan excelentes como las de Jaime Siles puede que yo también me anime a publicar mis homenajes a Catulo, para mí el poeta latino más memorable, puesto que es el poeta del que puedo citar más versos par coeur, o sea, de corazón y de memoria. Este chiste más que de Cardenal es de Papa. Sea la paz entre los traductores. Como decía con un retruécano semejante al mío nuestro antepenúltimo pontífice, lo importante es la concordia, no el 
QUINCE POEMAS DE CATULO

concordato. O factun male! Ayer regalé el Diccionario de términos filológicos de Lázaro Carreter -quien por cierto me echó una pequeña bronca cuando era decano por unas palabrillas que tuve con un catedrático- y ahora tendría que consultar qué es un retruécano. 
Vivamus, mea Lesbia, atque amemus, rumoresque senum seueriorum omnes unius aestimemus assis! soles occidere et redire possunt: nobis cum semel occidit breuis lux, nox est perpetua una dormienda. da mi basia mille, deinde centum, dein mille altera, dein secunda centum, deinde usque altera mille, deinde centum. dein, cum milia multa fecerimus, conturbabimus illa, ne sciamus, aut ne quis malus inuidere possit, cum tantum sciat esse basiorum. 
QUINCE POEMAS DE CATULO

Vivamos, Lesbia mía, y amémonos

y no nos importen un as todos los chismes

de los ancianos más ceñudos.

Los soles pueden ponerse y renacer.

Pero nosotros, una vez que se extinga nuestra breve luz, una noche perpetua tenemos que dormir.

Dame mil besos, luego cien, luego otros mil, cien más después, y otra vez mil seguidos y otros cien.

$Y$ cuando hayamos sumado muchos miles embrollaremos la cuenta para no saberla y para que ningún malvado pueda aojarnos si supiera que tanto nos besamos. 
RAMON IRIGOYEN

VII

Quaeris, quot mihi basiationes

tuae, Lesbia, sint satis superque.

quam magnus numerus Libyssae harenae

lasarpiciferis iacet Cyrenis

oraclum Iouis inter aestuosi

et Batti ueteris sacrum sepulcrum;

aut quam sidera multa, cum tacet nox,

furtiuos hominum uident amores:

tam te basia multa basiare

uesano satis et super Catullo est,

quae nec pernumerare curiosi

possint nec mala fascinare lingua. 
QUINCE POEMAS DE CATULO

Me preguntas, Lesbia, cuántos besos tuyos serían suficientes para mí.

Tan gran número como las arenas de Libia se extienden por Cirene, rica en laserpicio, entre el oráculo del ardiente Júpiter y el sepulcro sagrado del viejo Bato;

o tantos como estrellas ven, cuando calla la noche, los furtivos amores de los hombres:

le bastaría al loco de Catulo

que tú le dieras tantos besos

que contar no pudieran los curiosos

ni con su perniciosa lengua aojarlos. 
RAMON IRIGOYEN

\section{VIII}

Miser Catulle, desinas ineptire, et quod uides perisse perditum ducas. fulsere quondam candidi tibi soles, cum uentitabas quo puella ducebat amata nobis quantum amabitur nulla. ibi illa multa cum iocosa fiebant, quae tu uolebas nec puella nolebat, fulsere uere candidi tibi soles. nunc iam illa non uolt: tu quoque inpotens noli, nec quae fugit sectare, nec miser uiue, sed obstinata mente perfer, obdura. uale, puella. iam Catullus obdurat, nec te requiret nec rogabit inuitam. at tu dolebis, cum rogaberis nulla. scelesta, uae te, quae tibi manet uita? quis nunc te adibit? cui uideberis bella? quem nunc amabis? cuius esse diceris? quem basiabis? cui labella mordebis? at tu, Catulle, destinatus obdura. 
QUINCE POEMAS DE CATULO

8

Pobre Catulo, deja de hacer el tonto, y lo que ves que ha muerto dalo ya por perdido.

En tiempos brillaron para ti soles radiantes, cuando acudías a donde te llevaba una muchacha por mí amada como ninguna ya será querida.

Entonces eran realidad goces sin cuento, que tú querías y que no rehusaba tu muchacha. De veras que brillaron para tí soles radiantes:

Ahora ella ya no quiere: tú, ya sin control, no lo quieras tampoco ni la persigas en su huida, ni vivas desdichado, sino que con obstinado ánimo resiste, hazte duro. Adiós, muchacha. Ya Catulo se ha endurecido, ya no te buscará ni solicitará contra tu voluntad. Pero tú sufrirás, cuando ya nadie te requiera. ¡Ay de ti, maldita! ¡Qué vida te espera! ¿Quién se te acercará ahora? ¿A quién parecerás hermosa? ¿A quién querrás ahora? ¿De quién dirán que eres? ¿A quién vas a besar? ¿A quién le moderás los labiecitos? Pero tú, Catulo, tenaz mantente duro. 
Varus me meus ad suos amores uisum duxerat e foro otiosum, scortillum, ut mihi tum repente uisum est, non sane illepidum neque inuenustum.

huc ut uenimus, incidere nobis sermones uarii, in quibus, quid esset iam Bithynia, quo modo se haberet, et quonam mihi profuisset aere. respondi id quod erat, nihil neque ipsis nec praetoribus esse nec cohorti, cur quisquam caput unctius referret, praesertim quibus esset irrumator praetor, nec faceret pili cohortem. 'at certe tamen', inquiunt 'quod illic natum dicitur esse, comparasti ad lecticam homines.' ego, ut puellae unum me facerem beatiorem, 'non' inquam 'mihi tam fuit maligne, ut, prouincia quod mala incidisset, non possem octo homines parare rectos.' at mi nullus erat nec hic neque illic, fractum qui ueteris pedem grabati in collo sibi collocare posset. hic illa, ut decuit cinaediorem, 'quaeso', inquit 'mihi, mi Catulle, paulum istos commoda: nam uolo ad Serapim deferri.' 'mane', inquii puellae, 'istud quod modo dixeram me habere, fugit me ratio: meus sodalisCinna est Gaius,--is sibi parauit. uerum, utrum illius an mei, quid ad me? utor tam bene quam mihi pararim. set tu insulsa male et molesta uiuis, per quam non licet esse neglegentem.' 
QUINCE POEMAS DE CATULO

10

Mi Varo me llevó del foro --yo nada hacía allía hacer una visita a su amor, una putilla, según me pareció al instante, no del todo sin gracia y sin donaire. En cuan to llegamos, tocamos varias conversaciones, y entre otras cómo era Bitinia, en qué estado se hallaba, y si en cuanto a dinero me había aprovechado. Respondí la verdad: que ni los nativos ni los pretores ni su séquito tenían medios para regresar con la cabeza mejor perfumada, y en especial los que tenían por pretor a un mamón, a quien su séquito le importaba un comino. "Pero al menos, dijeron, adquiriste lo que dicen que es un producto del país: hombres para tu litera." Yo por pasar ante la chica como particularmente afortunado le dije: "no me ha ido tan mal que, porque me tocara una mala provincia, no pudiera adquirir ocho hombres de buena planta." Pero yo no tenía ni aquí ni allí uno solo que pudiera cargarse al hombro la pata rota de un viejo camastro. Y entonces ella, como correspondía a una buena golfa, me dice: "Catulo mío, por favor, préstamelos un rato: quiero que me lleven al templo de Serapis." "Espera, le dije a la muchacha, en esto que acabo de decirte que tenía se me fue la mente: es Cinna Gayo, un camarada mío; él los compró. Pero que sean míos o de él, ¿a mí qué?

Los utilizo como si fuera yo su comprador. $Y$ tú eres una sosa y una pesada con quien uno no puede descuidarse." 
RAMON IRIGOYEN

\section{XI}

Furi et Aureli, comites Catulli, siue in extremos penetrabit Indos, litus ut longe resonante Eoa tunditur unda, siue in Hyrcanos Arabasue molles, seu Sagas sagittiferosue Phartos, siue quae septemgeminus colorat aequora Nilus,

siue trans altas gradietur Alpes, Caesaris uisens monimenta magni, Gallicum Rhenum horribilesque ultimosque Britannos,

omnia haec, quaecumque feret uoluntas caelitum, temptare simul parati, pauca nuntiate meae puellae non bona dicta.

cum suis uiuat ualeatque moechis, quos simul complexa tenet trecentos, nullum amans uere, sed identidem omnium ilia rumpens;

nec meum respectet, ut ante, amorem, qui illius culpa cecidit uelut prati ultimi flos, praetereunte postquam tactus aratro est. 


\section{1}

Furio y Aurelio, compañeros de viaje de Catulo, ya haya de penetrar hasta las lindes de la India, donde la costa es batida por las olas de Oriente que a lo lejos retumban,

o hasta el país de los hircanos o los lánguidos árabes,

o los sagas o los partos armados de flechas,

o las llanuras que tiñe el Nilo

de siete bocas,

o si ha de atravesar los altos Alpes

para ir a ver los trofeos del gran César,

el Rin de Galia y los salvajes britanos,

los hombres más remotos,

si estáis dispuestos a afrontar todo esto, cualquier cosa que la voluntad de los dioses me depare, anunciad a mi amada estas pocas palabras

nada buenas:

que viva y que le vaya bien con sus macarras, esos trescientos que ella posee a la vez entre sus brazos, sin querer a ninguno de verdad, pero quebrantándoles a todos sin cesar los ijares;

y que ya no piense, como antes, en mi amor que por su culpa cayó como una flor en la linde de un prado, cuando el arado la alcanzó al pasar. 
RAMON IRIGOYEN

XVII

O Colonia, quae cupis ponte ludere longo, et salire paratum habes, sed uereris inepta crura ponticuli axulis stantis in rediuiuis, ne supinus eat cauaque in palude recumbat: sic tibi bonus ex tua pons libidine fiat, in quo uel Salisubsali sacra suscipiantur, munus hoc mihi maximi da, Colonia, risus. quendam municipem meum de tuo uolo ponte ire praecipitem in lutum per caputque pedesque, uerum totius ut lacus putidaeque paludis liuidissima maximeque est profunda uorago. insulsissimus est homo, nec sapit pueri instar bimuli tremula patris dormientis in ulna. cui cum sit uiridissimo nupta flore puella et puella tenellulo delicatior haedo, adseruanda nigerrimis diligentius uuis, ludere hanc sinit ut lubet, nec pili facit uni, nec se subleuat ex sua parte, sed uelut alnus in fossa Liguri iacet suppernata securi, tantundem omnia sentiens quam si nulla sit usquam; talis iste meus stupor nil uidet, nihil audit, ipse qui sit, utrum sit an non sit, id quoque nescit. nunc eum uolo de tuo ponte mittere pronum, si pote stolidum repente excitare ueternum, et supinum animum in graui derelinquere caeno, ferream ut soleam tenaci in uoragine mula. 
Oh Colonia, que deseas divertirte en tu largo puente, y tienes decidido danzar en él, pero temes las patas inseguras de ese puentecillo que se sostiene sobre estacas de derribo, no sea que se desplome y se hunda en el fondo de la laguna; ojalá te hagan un buen puente a tu gusto, en el que puedan celebrarse hasta los ritos de los salisubsilios; ofréceme, Colonia, este espectáculo de la mayor irrisión. Quiero que cierto paisano mío desde tu puente se precipite en el fango de pies a cabeza, pero allí donde el abismo de todo el lago y de tu pestilente laguna es más negro y profundo.

Es idiota del todo, $\mathrm{y}$ no tiene sentido, igual que un niño de dos años que duerme acunado en los brazos de su padre; pues estando casado con una muchacha en su flor más lozana, una muchacha más delicada que un tierno cabritillo, y a la que hay que guardar con más cuidado que a las uvas más maduras, la deja solazarse a su antojo, y no le importa un bledo, y no se mueve de su sitio, sino que igual que un olmo talado por el hacha ligur yace en un hoyo, sensible a todo exactamente igual que si ella no existiera, ese imbécil mío nada ve, nada oye, su identidad incluso ignora, y hasta si exsite o no.

A éste quiero ahora yo arrojar desde tu puente de cabeza, a ver si puede de una vez despertar de su estúpida modorra y dejar su zángana alma en el pesado barro como en un bache pegajoso su suela de hierro deja una mula. 


\title{
RAMON IRIGOYEN
}

\begin{abstract}
XXII
Suffenus iste, Vare, quem probe nosti, homo est uenustus et dicax et urbanus, idemque longe plurimos facit uersus. puto esse ego illi milia aut decem aut plura perscripta, nec sic ut fit in palimpseston relata: cartae regiae, noui libri, noui umbilici, lora rubra membranae, derecta plumbo et pumice omnia aequata. haec cum legas tu, bellus ille et urbanus Suffenus unus caprimulgus aut fossor rursus uidetur: tantum abhorret ac mutat. hoc quid putemus esse? qui modo scurra aut si quid hac re scitius uidebatur, idem infaceto est infacetior rure, simul poemata attigit, neque idem umquam aeque est beatus ac poema cum scribit: tam gaudet in se tamque se ipse miratur. nimirum idem omnes fallimur, neque est quisquam quem non in aliqua re uidere Suffenum possis. suus cuique attributus est error; sed non uidemus manticae quod in tergo est.
\end{abstract}


QUINCE POEMAS DE CATULO

Ese Sufeno, Varo, que conoces tan bien, es hombre con donaire, educado y agudo, y compone además innumerables versos. Creo que él tiene escritos diez mil versos o más, y no, como es corriente, en palimpsesto los copió: papel real, nuevos volúmenes, varillas nuevas, correas encarnadas para el pergamino, todo rayado al plomo y alisado con piedra pómez. Cuando los leas, por el contrario ese educado y fino Sufeno ha de parecerte un vulgar cabrero o cavador: tanto cambia y se aparta de su ser. ¿Qué pensaremos que sucede? El que nos parecía hace un momento un hombre con gracia, o incluso algo aún más refinado, es más grosero que un grosero gañán en cuanto toca un verso. Y él jamás es tan feliz como cuando compone un poema:

tanto en sí mismo se complace, tanto se admira. La verdad es que todos caemos en lo mismo, y no hay nadie en quien no puedas ver en cierto modo un Sufeno. A cada uno se le asignó un defecto, mas no vemos la alforja que a la espalda llevamos. 
RAMON IRIGOYEN

\section{XXXII}

Amabo, mea dulcis Ipsitilla meae deliciae, mei lepores, iube ad te ueniam meridiatum. et si iusseris, illud adiuuato, ne quis liminis obseret tabellam, neu tibi lubeat foras abire, sed domi maneas paresque nobis nouem continuas fututiones. uerum si quid ages, statim iubeto: nam pransus iaceo et satur supinus pertundo tunicamque palliumque. 
QUINCE POEMAS DE CATULO

Por favor, dulce Ipsitila mía, mi delicia y donaire, invitame a tu casa a echar la siesta.

$Y$ si me invitas, hazme este otro favor: que nadie eche el cerrojo a tu puerta, ni te apetezca salir fuera, sino que estate en casa dispuesta a echar conmigo nueve polvos seguidos.

Pero, si accedes, invítame ahora mismo:

pues he comido ya y, bien lleno, estoy tumbado boca arriba y perforo la túnica y el manto. 
RAMON IRIGOYEN

XLI

Ameana puella defututa tota milia me decem poposcit, ista turpiculo puella naso, decoctoris amica Formiani. propinqui, quibus est puella curae, amicos medicosque conuocate: non est sana puella, nec rogate qualis sit: solet esse imaginosa. 
QUINCE POEMAS DE CATULO

41

Ameana, esa muchacha tan follada, me pidió diez mil sestercios íntegros, esa muchacha de nariz tan feúcha, la amiga del dilapidador de Formias. Parientes que cuidáis a la muchacha llamad a los amigos y a los médicos. La chicha no está bien y no le preguntéis qué tal se encuentra: suele sufrir alucinaciones. 
RAMON IRIGOYEN

\section{LI}

Ille mi par esse deo uidetur, ille, si fas est, superare diuos, qui sedens aduersus identidem te spectat et audit

dulce ridentem, misero quod omnis eripit sensus mihi: nam simul te, Lesbia, aspexi, nihil est super mi vocis in ore,

lingua sed torpet, tenuis sub artus flamma demanat, sonitu suopte tintinant aures, gemina teguntur lumina nocte.

otium, Catulle, tibi molestum est: otio exsultas nimiumque gestis: otium et reges prius et beatas perdidit urbes. 
QUINCE POEMAS DE CATULO

51

Me parece que se asemeja a un dios

$-y$, si no es sacrilegio, quese halla por encima delos diosesquien frente a ti sentado sin cesar te contempla y te oye

reír tan dulcemente: risa que a mí, infeliz, todos los sentidos me arrebata: pues, apenas te veo, Lesbia, yo me quedo sin voz en esta boca,

la lengua se me traba; por mis miembros se esparce una llama sutil y con su son tan peculiar me zumban los oídos; una noche gemela vela mis pupilas.

Catulo, el ocio es para ti funesto; en el ocio te exaltas y te acaloras demasiado; el ocio, en otro tiempo, perdió a reyes $\mathrm{y}$ a ciudades felices. 
RAMON IRIGOYEN

LVI

$\mathrm{O}$ rem ridiculam, Cato, et iocosam dignamque auribus et tuo cachinno! ride quidquid amas, Cato, Catullum: res est ridicula et nimis iocosa. deprendi modo pupulum puellae trusantem; hunc ego, si placet Dionae, pro telo rigida mea cecidi. 
QUINCE POEMAS DE CATULO

56

¿Qué cosa más ridícula y chistosa, Catón, digna de tus oídos y tus risas!

Ríe, Catón, por tu amor a Catulo:

la cosa es de risa y por demás chistosa.

Acabo de sorprender a un mozuelo montando

a una chiquilla y - ¡válgame Diona!-

caí sobre él con la mía -como un dardo-bien tiesa. 
RAMON IRIGOYEN

LVIII

Caeli, Lesbia nostra, Lesbia illa, illa Lesbia, quam Catullus unam plus quam se atque suos amauit omnes, nunc in quadriuiis et angiportis glubit magnanimi Remi nepotes. 
QUINCE POEMAS DE CATULO

58

Celio, mi Lesbia, la Lesbia aquella, aquella Lesbia, que Catulo amó más, a ella sola, que a sí mismo y que a todos los suyos, ahora en callejones y esquinas

se la mama a los nietos del magnánimo Remo. 
RAMON IRIGOYEN

\section{LXXII}

Dicebas quondam solum te nosse Catullum, Lesbia, nec prae me uelle tenere Iouem. dilexi tum te non tantum ut uulgus amicam, sed pater ut gnatos diligit et generos.

nunc te cognoui: quare etsi impensius uror, multo mi tamen es uilior et leuior.

qui potis est, inquis? quod amantem iniuria talis cogit amare magis, sed bene uelle minus. 
QUINCE POEMAS DE CATULO

Decías, Lesbia, en tiempos que sólo conocías a Catulo y que ni al mismo Júpiter querrías poseer antes que a mí. Te amé entonces no sólo como el vulgo ama a su amante, sino como un padre quiere a sus hijos y a sus yernos.

Al fin te he conocido: por eso aunque me abraso con mayor violencia para mí eres mucho más miserable y despreciable.

¿Cómo es posible, dices? Porque un agravio semejante obliga a un enamorado a querer más, pero a sentir menos cariño. 
RAMON IRIGOYEN

\section{LXXXV}

Odi et amo, quare id faciam, fortasse requiris? nescio, sed fieri sentio et excrucior. 
QUINCE POEMAS DE CATULO

Odio y amo. Tal vez preguntes por qué lo hago. No lo sé, pero siento que es así y me torturo. 
RAMON IRIGOYEN

\section{LXXXVI}

Quintia formosa est multis, mihi candida, longa, recta est: haec ego sic singula confiteor. totum illud formosa nego: nam nulla uenustas, nulla in tam magno est corpore mica salis.

Lesbia formosa est, quae cum pulcerrima tota est, tum omnibus una omnis surripuit Veneres. 
QUINCE POEMAS DE CATULO

86

Quintia para muchos es guapa: para mí es blanca, alta, derecha. Yo le reconozco uno por uno estos encantos, pero que sea plenamente guapa yo lo niego:

porque en un cuerpo tan gallardo

no hay nada de donaire ni una pizca de sal.

Lesbia sí es hermosa, pues siendo toda ella bellísima, además ella sola a todas les quitó todas sus gracias. 
